\title{
Determinants of preterm birth among mothers delivered in Central Zone Hospitals, Tigray, Northern Ethiopia
}

\author{
Tesfay Berhe ${ }^{1 *}$, Hailay Gebreyesus ${ }^{1,2}$ and Haftom Desta ${ }^{3}$
}

\begin{abstract}
Objective: Preterm deliveries were responsible for 3.1 million neonatal deaths that occurred globally in 2010, of them $35 \%$ were directly related to preterm. This study was aimed to assess the determinants of preterm birth among women delivered of Central zone. A facility-based cross-sectional study was carried out from March to May 2018, in four randomly selected hospitals of Central zone. A total of 413 participants were interviewed using a pre-tested structured questionnaire. Data were entered into Epi-info Version 3.5.3 and then exported to SPSS Version 21 for analysis. Bivariate and multivariate logistic regression analysis was carried out to assess the association. Statistical significance was declared by $95 \%$ confidence interval of the odds ratio.

Result: From the total (413) participants, $78.7 \%$ of participants were in the age group of 20-34 years and in this study the prevalence of preterm birth was 12.8\%. Factors like, marital status of unmarried ( $A O R=5.21,95 \% \mathrm{Cl} 1.8-15.075$ ), mid upper arm circumference (MUAC) $(<11 \mathrm{~cm})(A O R=2.42,95 \% \mathrm{Cl} 1.204-4.851)$ were independent predictors of preterm birth among women delivered in the study area.
\end{abstract}

Keywords: Determinants, Preterm birth, Pregnant women, Gestational age, Newborn

\section{Introduction}

Preterm birth defined as live births before 37 completed weeks of gestational age [1-3]. From the 130 million babies born each year globally, approximately 15 million are born preterm and $60 \%$ of preterm is occur in developing countries [4-6]. The risk of neonatal death in African baby is higher than European baby by at least 12 times due to complications of preterm birth. By comparing of economic status, over $90 \%$ of extremely preterm babies ( $<28$ weeks) born in low-income countries die within the first few days of life while only less than $10 \%$ of babies of this gestation die in high-income settings [5, 7].

In Ethiopia 320,000 preterm births are happening every year [8]. Under-5 mortality rates are reducing in many countries and Ethiopia also achieved the millennium development goal on child mortality reduction. However,

\footnotetext{
*Correspondence: alnorasanti@gmail.com

1 Department of Public Health, College of Health Sciences, Aksum University, P. O. Box: 298, Aksum, Ethiopia

Full list of author information is available at the end of the article
}

neonatal mortality rate have been shown much less progress. Neonatal deaths account for an increasing proportion of child deaths worldwide $(41 \%$ in 2015) much higher than the $38 \%$ in 2000 [9-12]. About 15 million babies born too early each year, that is more than one in ten births. Every year around one million children die due to the consequence of prematurity birth $[3,8,13]$.

Even though, many women have a premature birth, its risk factor is idiopathic. But it can be occurred due to many risk factors. These could be: history of premature birth, multiple pregnancies, short spacing between pregnancies (mainly less than 6 months), troubles with the uterus, substance use like drug or cigarette, low intake of nutrients, in adequate increasing of weight during the period of pregnancy, complication due to infections and some of the non-communicable diseases [14].

From the total, about $85 \%$ of preterm babies are delivered between 32 week and 37 weeks of gestation. These babies do not need intensive care for their survival. In Ethiopia, which is one of the developing country, about 320,000 babies are born very early each year and around 
24,400 less than 5 year children die due to direct effect of preterm $[8,15]$. The main cause of neonatal morbidity and mortality and the occurrence of preterm birth are considered a complex public health condition. With variable incidence in several countries, it has grown markedly in the last decades [16]. Therefore, it is essential to establish the prevalence and causes of this condition in order to propose prevention actions.

\section{Main text \\ Methods \\ Study setting}

The study was carried out at public hospitals of Central zone which is found in Tigray regional state. It is located at $1040 \mathrm{~km}$ far from Addis Ababa, capital city of Ethiopia to the North. The total population of the zone is $1,347,212$, of which about 686,161 are female (according to zonal 2017 official report). Administratively, it is divided into 8 districts and has nine hospitals.

\section{Study design and population}

This study was done using a facility-based cross-sectional study design from March to May 2018. The respondents of this study were women who gave births a baby in the hospitals and who lived in the central zone for at least 6 months were included in the study. Those women who did not responses appropriately the interview due to physical or mental illness were excluded from the study.

\section{Sample size and sampling technique}

The sample size of this study was calculated using a single proportion formula as follow:

$$
\mathrm{n}=\left(\mathrm{z} \alpha^{2}\right) \mathrm{p}(1-\mathrm{p}) / \mathrm{d}^{2}
$$

where $n=$ number of the study subjects (sample size), $\mathrm{Z}=$ standardized normal distribution value for the $95 \%$ confidence level (1.96), $d=$ Margin of error taken (0.05), $\mathrm{p}=$ prevalence of preterm birth from previous study (14.3\% [15]. Based on the above assumptions, by using of 2 design effect and $10 \%$ non-response, the final sample size becomes 413 .

In this study four hospitals were randomly selected from the nine hospitals of Central zone. Later, systematic sampling technique was being employed for selection of the participants. Study subjects were selecting every two mothers until the sampled population fills. Selection of the first sample was taken through simple random lottery method. All mothers who gave births in the selected hospitals during the specific study period were used as the study population.

\section{Operational definition}

Districts: small Administrative sub-zones.

History of poor obstetric outcome: mothers who had history of LBW, preterm birth, still birth, perinatal death and abortion.

Kebelles: small administrative unit in Ethiopia.

Preterm birth: live births before 37 completed weeks of gestational age.

\section{Data collection tools and procedure}

A structured, pretested and quantitative interviewer administered questionnaire was adopted by reviewing different literatures. The questionnaire was grouped into six categories; socio-demographic information, gynecological and obstetric, new born, medical disorder, nutritional and heath care related factors. The questionnaire was prepared in English and then translated into Tigrigna version and then translated back to English for its consistency and completeness.

To maintain data quality, data were collected by Clinical midwife and MPH in public health supervisors. Both of data collectors and supervisors were trained for 2 days to ensure the quality of data including clarification of questions to make simple and easily understandable, to use recommended ways of sampling technique and to inform the study subjects based on the consent. Four clinical midwives were collected the data by face to face interview immediately after birth and retrieved the remaining data from medical records. Two MPH in public health supervised the data collector's and they had been communicated daily with the authors. The questionnaire was tested for its clarity, consistency and unambiguous language in the one selected hospital which was not included in the study and appropriate modification had done based on findings. Supervisors and authors were strictly followed the data collection process and filled questionnaire were reviewed daily for completeness and consistency.

\section{Data processing and analysis procedures}

After data collection was made, each questionnaire had checked manually for its completeness before entering into software. The data was entered, cleaned and coded using Epi-data version 3.5.3 and data analysis was done using SPSS version 21. The data was described using frequency tables and descriptive statistics. The association between dependent and independent factors was analyzed using binary logistic regression analysis with crude Odds Ratio along with 95\% confidence interval, then these factors with $p$ value $<0.25$ analyzed using multivariate logistic regression analysis to determine the associated factors with preterm birth and to control 
confounding factors. In multivariate analysis, variables having $\mathrm{p}$-value less than 0.05 and adjusted odds ratio with 95\% CI were considered as significantly associated with the outcome variables.

\section{Result}

Socio-demographic characteristics of respondents

Out of the 413 mothers, a total of 410 (99\%) mothers participated in the study. Three hundred six (74.1\%) were in the age group between 20 and 34 years. About 390 (94.4\%) of the participants were Orthodox Christian followers and 397 (96.1\%) were married. Regarding maternal educational status $258(62.4 \%)$ were secondary and above and 198 (48\%) were house wife. About 187 (45.3\%) of the participants their family monthly income were in the range of $89-178.5 \$$ (Table 1).

\section{Gynecological and obstetric and new born characteristics of respondents}

From the total respondents 293 (70.9\%) were multipara. Most of the mothers 332 (80.4\%) received ANC four times and above, $330(80 \%)$ initiated ANC at first trimester of the current pregnancy, 374 (90.6\%) were taken iron supplementation, 290 (77.5\%) were taken iron

Table 1 Distribution of socio-demographic characteristics
of respondents in Central zone, Northern Ethiopia, 2018

\begin{tabular}{|c|c|c|}
\hline Variables & Number & Percent \\
\hline \multicolumn{3}{|l|}{ Maternal age } \\
\hline$<20$ & 48 & 11.6 \\
\hline $20-34$ & 325 & 78.7 \\
\hline $35+$ & 40 & 9.7 \\
\hline \multicolumn{3}{|l|}{ Religion } \\
\hline Orthodox & 390 & 94.4 \\
\hline Muslim & 23 & 5.6 \\
\hline \multicolumn{3}{|l|}{ Marital status } \\
\hline Single & 16 & 3.9 \\
\hline Married & 39 & 96.1 \\
\hline \multicolumn{3}{|c|}{ Maternal educational status } \\
\hline Illiterate & 56 & 13.6 \\
\hline Elementary & 99 & 24 \\
\hline Secondary and above & 258 & 62.4 \\
\hline \multicolumn{3}{|l|}{ Maternal occupation } \\
\hline Housewife & 198 & 48 \\
\hline Daily laborer & 26 & 6.3 \\
\hline Employed & 97 & 23.5 \\
\hline Merchant & 92 & 22.2 \\
\hline \multicolumn{3}{|l|}{ Income } \\
\hline$<89 \$$ & 101 & 24.5 \\
\hline $89 \$-178.5 \$$ & 187 & 45.3 \\
\hline$>178.5 \$$ & 125 & 30.2 \\
\hline
\end{tabular}

supplementation for less 3 months and from the pregnancies 383 (92.7\%) were planned. Three hundred fifty-five (86\%) were gave birth between 37 and 42 weeks of gestational age, where as $53(12.8 \%)$ and $5(1.2 \%)$ were gave birth in $<37$ weeks and $>42$ weeks, respectively. Majority of mothers 287 (69.5\%) were counseled to take additional diet, 286 (69.3\%) were took additional diet during current pregnancy. Four hundred two (97.3\%) mothers were not faced any pregnancy related complication during current pregnancy. Of the total births 400 (96.9\%) were live births and 13 (3.1\%) were stillbirths. Regarding birth weight 59 (14.7\%) newborns were low birth weight and related to maturity $51(12.3 \%)$ were preterm. Besides $9(2.2 \%)$ of all births were with visible birth defect (Table 2).

\section{Predictors of preterm birth}

After the bivariate logistic regression, multivariate logistic regression was employed to identify the independent predictors of preterm birth among mothers delivered in the hospital. Accordingly, marital status (unmarried) $(\mathrm{AOR}=5.21,95 \% \mathrm{CI} 1.8-15.075)$, mid upper arm circumference MUAC $(<11 \mathrm{~cm})(\mathrm{AOR}=2.42,95 \% \mathrm{CI}$ 1.204-4.851) were found to be significantly associated with preterm birth among mothers delivered in the hospitals (Table 3 ).

\section{Discussion}

Preterm birth remains a significant cause of morbidity and mortality among neonates and children. According to the 2016 Ethiopian Demographic health survey (EDHS), neonate mortality was 29 per 1000 live births. Among these causes of mortalities, preterm births were the major factor [17]. This facility-based study aimed to assess determinants of preterm births, in order to contribute to tackling morbidity and mortality related preterm births. According the findings of this study, prevalence of preterm birth were $12.8 \%$. This preterm birth finding is similar to a study conducted at Brazil (12.3\%), Kenya $(12.3 \%)[18,19]$. But this finding is lower than the study of preterm at Oromia regional state Ethiopia, Bangladeshi, Nigeria, India, Zimbabwe, Malawi and several Northern European countries which shows 25.9\%, 22.3\%, $18.35,15 \%, 16.4 \%, 16.8,18.1 \%$ respectively $[20-26]$ and little bit lower from the study done at Gondar university hospital and Tanzania which shows 14.2 and 14.3\% respectively $[15,27]$. This variation might be due to the difference in study area and period, improvements in the health care seeking behavior due to continuous education and improvements in the quality of health care provided to pregnant mothers. However, this finding is higher than the finding in Addis Ababa (7.1\%), Debre Markos (11.6\%) $[28,29]$. It might be shown that our country Ethiopia 
Table 2 Gynecological, obstetric and nutritional characteristics of respondents in Central zone, Northern Ethiopia, 2018

\begin{tabular}{|c|c|c|}
\hline Variables & Frequency & Percent \\
\hline \multicolumn{3}{|l|}{ ANC visit } \\
\hline Less than four & 81 & 19.6 \\
\hline Four and above & 332 & 80.4 \\
\hline \multicolumn{3}{|l|}{ Parity } \\
\hline Primigravid & 120 & 29.1 \\
\hline Multigravid & 293 & 70.9 \\
\hline \multicolumn{3}{|c|}{ Gestational age at delivery (weeks) } \\
\hline$<37$ & 53 & 12.8 \\
\hline $37-42$ & 355 & 86 \\
\hline $42+$ & 5 & 1.2 \\
\hline \multicolumn{3}{|c|}{ Counseling on additional diet } \\
\hline Yes & 287 & 69.5 \\
\hline No & 126 & 30.5 \\
\hline \multicolumn{3}{|l|}{ Additional diet } \\
\hline Yes & 286 & 69.3 \\
\hline No & 127 & 30.7 \\
\hline \multicolumn{3}{|l|}{ Pregnancy status } \\
\hline Planned & 383 & 92.7 \\
\hline Unplanned & 30 & 7.3 \\
\hline \multicolumn{3}{|c|}{ Any medical disorder } \\
\hline Yes & 23 & 5.6 \\
\hline No & 390 & 94.4 \\
\hline \multicolumn{3}{|c|}{ Hemoglobin level (md/dl) } \\
\hline$<11$ & 17 & 4.1 \\
\hline$\geq 11$ & 396 & 95.9 \\
\hline \multicolumn{3}{|l|}{ Height of mother } \\
\hline$\leq 1.49 \mathrm{~m}$ & 41 & 9.9 \\
\hline $1.50-1.55 \mathrm{~m}$ & 80 & 19.4 \\
\hline$\geq 1.55$ & 292 & 70.7 \\
\hline \multicolumn{3}{|l|}{ MUAC (cm) } \\
\hline$<21$ & 96 & 23.2 \\
\hline $21-23$ & 75 & 18.2 \\
\hline$\geq 23$ & 242 & 58.6 \\
\hline \multicolumn{3}{|l|}{ Ambulance service } \\
\hline Yes & 251 & 60.8 \\
\hline No & 162 & 39.2 \\
\hline \multicolumn{3}{|c|}{ Birth weight of live birth (g) } \\
\hline$<2500$ & 59 & 14.7 \\
\hline$\geq 2500$ & 341 & 85.3 \\
\hline \multicolumn{3}{|c|}{ Maturity of live birth } \\
\hline Preterm & 45 & 11.3 \\
\hline Term & 355 & 88.7 \\
\hline
\end{tabular}

brings change in health status of the mother and new born.

In the multivariable analysis marital status and MUAC measurement were significantly associated with preterm
Table 3 Factors associated with preterm birth among deliveries in Central zone, Northern Ethiopia, 2018

\begin{tabular}{|c|c|c|c|c|}
\hline \multirow[t]{2}{*}{ Variables } & \multicolumn{2}{|l|}{ Pre-tem } & \multirow[t]{2}{*}{ COR } & \multirow[t]{2}{*}{ AOR } \\
\hline & $\begin{array}{l}\text { Yes } \\
\text { n (\%) }\end{array}$ & $\begin{array}{l}\text { No } \\
\text { n (\%) }\end{array}$ & & \\
\hline \multicolumn{5}{|l|}{ Age } \\
\hline$<20$ & $9(18.75)$ & $39(81.25)$ & 1 & 1 \\
\hline $20-35$ & $35(10.76)$ & $290(89.24)$ & $0.52(0.23-1.17)$ & $0.76(0.29-2.00$ \\
\hline$\geq 35$ & $3(7.50)$ & $37(92.50)$ & $0.35(0.09-1.40)$ & $0.39(0.06-2.82)$ \\
\hline \multicolumn{5}{|l|}{ Income } \\
\hline$<2500$ & $10(9.90)$ & $91(90.10)$ & $0.61(0.27-1.39)$ & $0.56(0.212-1.50)$ \\
\hline $2500-5000$ & $18(9.62)$ & 169 (90.38) & $0.59(0.30-1.18)$ & $0.58(0.26-1.27)$ \\
\hline$\geq 5000$ & $19(15.20)$ & $106(84.80)$ & 1 & 1 \\
\hline \multicolumn{5}{|l|}{ Marital status } \\
\hline Unmarried & $6(37.50)$ & $10(62.50)$ & $\begin{array}{c}5.21(1.80- \\
15.08)^{*}\end{array}$ & $4.01(1.17-13.71)^{* *}$ \\
\hline Married & $41(10.32)$ & $356(89.68)$ & 1 & 1 \\
\hline \multicolumn{5}{|c|}{ Maternal education } \\
\hline Illiterate & $5(6.30)$ & 74 (93.70) & $0.46(0.17-1.27)$ & $0.45(0.15-1.43)$ \\
\hline Primary & $21(12.35)$ & $149(87.65)$ & $0.96(0.50-1.83)$ & $0.85(0.41-1.77)$ \\
\hline $\begin{array}{l}\text { Secondary } \\
\text { and above }\end{array}$ & $21(12.80)$ & $143(87.20)$ & 1 & 1 \\
\hline \multicolumn{5}{|c|}{ Maternal occupation } \\
\hline House wife & $20(8.10)$ & $227(91.90)$ & 1 & 1 \\
\hline Daily laborer & $4(21.10)$ & 15 (78.90) & $3.03(0.92-10.00)$ & $2.87(0.76-10.79)$ \\
\hline Employed & $7(11.70)$ & $53(88.30)$ & $1.5(0.60-3.73)$ & $1.26(0.43-3.68)$ \\
\hline Merchant & $12(19.40)$ & $50(80.60)$ & $2.72(1.25-5.93)$ & $2.3(0.97-5.51)$ \\
\hline Student & $4(16.00)$ & $21(84.00)$ & $2.16(0.68-6.92)$ & $1.43(0.39-5.21)$ \\
\hline \multicolumn{5}{|l|}{ MUAC } \\
\hline$<21$ & $20(19.80)$ & $81(80.20)$ & $2.62(1.35-5.09)^{*}$ & $2.42(1.20-4.85)^{* *}$ \\
\hline $21-23$ & $6(8.80)$ & $62(91.20)$ & $1.03(0.40-2.66)$ & $1.1(0.41-2.76)$ \\
\hline$\geq 23$ & $21(8.60)$ & $223(91.40)$ & 1 & 1 \\
\hline \multicolumn{5}{|l|}{ Maternal height } \\
\hline$<150$ & $6(20.70)$ & $23(79.30)$ & $2.2(0.84-5.79)$ & $2.15(0.70-6.58)$ \\
\hline $150-155$ & $7(11.10)$ & $56(88.90)$ & $1.06(0.45-2.50)$ & $1.36(0.53-3.46)$ \\
\hline$\geq 155$ & $34(10.60)$ & $287(89.40)$ & 1 & 1 \\
\hline \multicolumn{5}{|l|}{ ANC visit } \\
\hline Less than four & $15(18.80)$ & $65(81.20)$ & $2.17(1.11-4.24)^{*}$ & $1.5(0.69-3.29)$ \\
\hline $\begin{array}{c}\text { Four and } \\
\text { above }\end{array}$ & $32(9.60)$ & $301(90.40)$ & 1 & 1 \\
\hline \multicolumn{5}{|l|}{ Pregnancy status } \\
\hline Planned & $40(10.50)$ & $342(89.50)$ & 1 & 1 \\
\hline Unplanned & $7(22.60)$ & $24(77.40)$ & $2.49(1.01-6.15)^{*}$ & $1.18(0.38-3.64)$ \\
\hline \multicolumn{5}{|c|}{ Counseling additional diet } \\
\hline Yes & $25(9.50)$ & $237(90.50)$ & 1 & 1 \\
\hline No & $22(14.60)$ & $129(85.40)$ & $0.96(0.48-1.93)$ & $0.57(0.29-1.14)$ \\
\hline \multicolumn{5}{|l|}{ Additional diet } \\
\hline Yes & $25(9.70)$ & $234(90.30)$ & 1 & 1 \\
\hline No & $22(14.30)$ & $132(85.70)$ & $1.93(1.02-3.64)^{*}$ & $1.09(0.55-2.16)$ \\
\hline \multicolumn{5}{|l|}{ Medical problem } \\
\hline Yes & $3(7.50)$ & $37(92.50)$ & $0.6(0.18-2.05)$ & $0.38(0.05-3.10)$ \\
\hline No & $44(11.80)$ & $329(88.20)$ & 1 & 1 \\
\hline
\end{tabular}

** Indicates statistically significant association at a $p$ value $<0.05$ 
births. The study found that being unmarried increased the risk of preterm birth by four folds than the married. This finding is consistent with the findings done at Michigan [30]. This might be due to financial insecurity, psychosocial stress and low health care utilization.

This study also showed that MUAC less than $11 \mathrm{~cm}$ was significantly associated with preterm birth (PTB). The proportion of preterm birth was significantly higher $(2.42$ times) among mothers who had MUAC less than $11 \mathrm{~cm}$ compared to mothers with MUAC greater than or equal to $23 \mathrm{~cm}$. This finding is consistent with the findings of studies done at Bangladeshi [31]. This might be maternal under nutritional status (mothers with $M U A C<11 \mathrm{~cm}$ ) before and during pregnancy may contribute for preterm.

\section{Conclusion}

The prevalence of preterm birth in this study was substantially high (12.8\%). Factors like marital status that are unmarried and MUAC with less than $11 \mathrm{~cm}$ were associated with preterm birth. The factors identified in this study can be prevented and managed easily by providing appropriate care before pregnancy, antepartum and intrapartum period.

\section{Limitation of the study}

The cross sectional nature of the data, which makes it impossible to draw inferences about the direction of relations among study variables and the data are retrospective and thus are subjected to recall bias.

\section{Abbreviations}

ANC: antenatal care; EC: Ethiopian Calendar; EDHS: Ethiopian Demographic and Health Survey; KM: kilometer; LBW: low birth weight; MUAC: Middle Upper Arm Circumference; MPH: Master of Public Health; MOH: Ministry of Health; $\mathrm{RH}$ : reproductive health; SPSS: Statistical Package for Social Science; USA: United States of America; WHO: World Health Organization.
\end{abstract}

\section{Acknowledgements}

Our heartfelt thank goes to Aksum University for financial support. We are thankful to Central zone for their positive responses to facilitate the study and all study participants who voluntarily participated in this study.

\section{Authors' contributions}

TB wrote the proposal, participated in data collection, analyzed the data, and drafted the paper. HG and HD approved the proposal, participated in data analysis and revised subsequent drafts of the paper. All authors read and approved the final manuscript.

\section{Funding}

This work was funded by Aksum University College of Health Science. The funded organization financed for data collection process including analysis and interpretation.

\section{Availability of data and materials}

The datasets in which conclusion taken is available in the form of Microsoft Excel. It is available on requesting.

\section{Ethics approval and consent to participate}

The study was approved by Aksum University, College of Health science, Research Ethics Committee. Permission letter was also obtained from central zone health office and was presented to all participants. Written consent was obtained after the potential participants were informed of the study's objectives and reading the information sheet. Only women who gave consent to participate were included in the study. All participants were also informed that they could withhold or withdraw from participation at any time, without any negative consequences. Interviews were conducted in private that guarantee optimum privacy. Confidentiality and privacy of the study were maintained during data collection, analysis, and reporting.

\section{Consent for publication}

Not applicable.

\section{Competing interests}

The authors declare that they have no competing interests.

\section{Author details}

${ }^{1}$ Department of Public Health, College of Health Sciences, Aksum University, P. O. Box: 298, Aksum, Ethiopia. ${ }^{2}$ Health Education and Promotion, Department of Public Health, College of Health Science, Aksum University, Aksum, Ethiopia. ${ }^{3}$ Department of Psychiatric Nursing, College of Health Sciences, Aksum University, Aksum, Ethiopia.

Received: 26 March 2019 Accepted: 4 May 2019

Published online: 14 May 2019

\section{References}

1. Kramer MS. The Epidemiology of adverse pregnancy outcomes: an overview departments of pediatrics and of epidemiology \& biostatistics. Montreal: McGill University Faculty of Medicine; 2003.

2. Demelash H, Motbainor A, Nigatu D, Gashaw K, Melese A. Risk factors for low birth weight in Bale zone hospitals, South-East Ethiopia: a case-control study. BMC Pregnancy Childbirth. 2015;15(1):264.

3. WHO. Preterm birth fact sheet. 2016.

4. March of Dimes/WHO. Born Too Soon-The global action report on preterm birth. 2012.

5. Blencowe $\mathrm{H}$, Cousens $\mathrm{S}$, Oestergaard $\mathrm{M}$, et al. National, regional and worldwide estimates of preterm birth rates in the year 2010 with time trends for selected countries since 1990: a systematic analysis. For CHERG/WHO, 2012.

6. Born too soon. The global action report for preterm birth, MoD, PMNCH, save the children. New York: WHO; 2012.

7. Institute of Medicine. Preterm birth: causes, consequences, and prevention. Washington, D.C.: National Academy Press; 2007.

8. Ethiopia profile of preterm and low birth weight prevention and care. http://www.EveryPreemie.org. Accessed May 2017

9. Lawn JE, Cousens S, Zupan J. Neonatal survival 14 million neonatal deaths: When? Where? Why? Lancet. 2009;2005(365):891-900.

10. Lawn JE, Kerber K, Enweronu-Laryea C, Massee Bateman O. Newborn survival in low resource settings - are we delivering? BJOG: Int J Obstet Gynaecol. 2009;1 16:49-59.

11. Health TFDRoEMo. Health Sector Transformation Plan 2015/16-2019/20 (2008-2012 EFY). 2015.

12. Rubens $C E$, Gravett MG, Victora CG, Nunes TM. Global report on preterm birth and stillbirth (7 of 7): mobilizing resources to accelerate innovative solutions (Global Action Agenda). BMC Pregnancy Childbirth. 2010;10(1):S7.

13. Kenya profile of preterm and low birth weight prevention and care. http://www.EveryPreemie.org. Accessed May 2017.

14. http://www.accessmedicine.com/resourceTOC.aspx? resourcelD=46. 2010.

15. Adane AA, Ayele TA, Ararsa LG, Bitew BD, Zeleke BM. Adverse birth outcomes among deliveries at Gondar University Hospital, Northwest Ethiopia. BMC Pregnancy Childbirth. 2014;14:90.

16. Preterm birth. Available from: https://academic.oup.com/epirev/artic leabstract/15/2/414/440477.

17. Program DHS. Ethiopia Demographic and Health Survey-2016. Rockville: ICF; 2016.

18. Do Carmo Leal M, Esteves-Pereira AP, Nakamura-Pereira M, Torres JA, Theme-Filha M, Domingues RM, Dias MA, Moreira ME, Gama SG. 
Prevalence and risk factors related to preterm birth in Brazil. Reprod Health. 2016;13(3):127.

19. The Global Action Report on Preterm Birth. Preterm Rate and Births Data. In: Blencowe H, Cousens S, Oestergaard MZ, Chou D, Moller A-B, Narwal R, Adler A, Garcia CV, Rohde SS, Say L, Lawn JE, editors. National, regional and worldwide estimates of preterm birth rates in the year 2010 with time trends for selected countries since 1990: a systematic ana lysis and implications. Geneva: World Health Organization; 2010.

20. Bekele I, Demeke T, Dugna K. Prevalence of preterm birth and its associated factors among mothers delivered in Jimma University Specialized Teaching and Referral Hospital, Jimma Zone, Oromia Regional State, South West Ethiopia. J Women's Health Care. 2017;6:356. https://doi org/10.4172/2167-0420.1000356.

21. Shah R, Mullany LC, Darmstadt GL, Mannan I, Rahman SM, Talukder RR, Applegate JA, Begum N, Mitra D, El Arifeen S, Baqui AH. Incidence and risk factors of preterm birth in a rural Bangladeshi cohort. BMC Pediatr. 2014;14(1):112.

22. Wagura P, Wasunna A, Laving A, Wamalwa D. Prevalence and factors associated with preterm birth at kenyatta national hospital. BMC Pregnancy Childbirth. 2018;18(1):107.

23. Shubhada A, Kambale SV, Phalke BD. Determinants of preterm labour in a Rural Medical College Hospital in Western Maharashtra. NJOG. 2013;8(1):31-3.

24. Feresu SA, Harlow SD, Welch K, Gillespie RW. Incidence of and sociodemographic risk factors for stillbirth, preterm birth and low birth weight among Zimbabwean women. Paediatr Perinat Epidemiol. 2004;18(2):154-63.
25. van den Broek Nynke R, Jean-Baptiste Rachel, Neilson James P. Factors associated with preterm, early preterm and late preterm birth in Malawi. PLoS ONE. 2014;9(3):e90128.

26. Beck S, Wojdyla D, Say L, Bertran AP, Meraldi M, et al. The worldwide incidence of preterm birth: a systematic review of maternal mortality and morbidity. Bull World Health Organ. 2010;88:31-8.

27. Temu TB, Masenga G, Obure J, Mosha D, Mahande MJ. Maternal and obstetric risk factors associated with preterm delivery at a referral hospital in northern-eastern Tanzania. Asian Pac J Reprod. 2016;5(5):365-70.

28. Koblinsky M, Tain F, Tesfaye S. Reducing maternal mortality and increasing use of skilled birth attendance: Ethiopia and MDG 5. Ethiop J Reprod Health. 2000;4(1):4-15.

29. Tigist B, Abdela A, Zenebe GK. Preterm birth and associated factors among mothers who gave birth in Debre Markos Town Health Institutions. Institutional Based Cross sectional study. 2013.

30. El-Sayed M, Tracy M, Galea S. Life course variation in the relation between maternal marital status and preterm birth. Epidemiology. 2012;22(3):168-74.

31. WHO. Maternal anthropometry and pregnancy outcomes: a WHO collaborative study. Bull World Health Organ. 1997;73(1):98.

\section{Publisher's Note}

Springer Nature remains neutral with regard to jurisdictional claims in published maps and institutional affiliations.
Ready to submit your research? Choose BMC and benefit from:

- fast, convenient online submission

- thorough peer review by experienced researchers in your field

- rapid publication on acceptance

- support for research data, including large and complex data types

- gold Open Access which fosters wider collaboration and increased citations

- maximum visibility for your research: over $100 \mathrm{M}$ website views per year

At BMC, research is always in progress.

Learn more biomedcentral.com/submissions 